Article

\title{
Application of Artificial Intelligence and Gamma Attenuation Techniques for Predicting Gas-Oil-Water Volume Fraction in Annular Regime of Three-Phase Flow Independent of Oil Pipeline's Scale Layer
}

\author{
Abdulaziz S. Alkabaa ${ }^{1}\left(\mathbb{D}\right.$, Ehsan Nazemi ${ }^{2, *(D)}$, Osman Taylan ${ }^{1}\left(\mathbb{D}\right.$ and El Mostafa Kalmoun ${ }^{3}(\mathbb{D}$ \\ 1 Department of Industrial Engineering, Faculty of Engineering, King Abdulaziz University, P.O. Box 80204, \\ Jeddah 21589, Saudi Arabia; aalkabaa@kau.edu.sa (A.S.A.); otaylan@kau.edu.sa (O.T.) \\ 2 Imec-Vision Lab, Department of Physics, University of Antwerp, 2610 Antwerp, Belgium \\ 3 Department of Mathematics, Statistics and Physics, College of Arts and Sciences, Qatar University, \\ Doha 2713, Qatar; ekalmoun@qu.edu.qa \\ * Correspondence: ehsan.nazemi@uantwerpen.be
}

\section{check for}

updates

Citation: Alkabaa, A.S.; Nazemi, E.; Taylan, O.; Kalmoun, E.M.

Application of Artificial Intelligence and Gamma Attenuation Techniques for Predicting Gas-Oil-Water Volume Fraction in Annular Regime of Three-Phase Flow Independent of Oil Pipeline's Scale Layer. Mathematics 2021, 9, 1460. https://doi.org/ $10.3390 /$ math 9131460

Academic Editor: Aihua Wood

Received: 19 May 2021

Accepted: 19 June 2021

Published: 22 June 2021

Publisher's Note: MDPI stays neutral with regard to jurisdictional claims in published maps and institutional affiliations.

Copyright: (c) 2021 by the authors. Licensee MDPI, Basel, Switzerland. This article is an open access article distributed under the terms and conditions of the Creative Commons Attribution (CC BY) license (https:/ / creativecommons.org/licenses/by/ $4.0 /)$.

\begin{abstract}
To the best knowledge of the authors, in former studies in the field of measuring volume fraction of gas, oil, and water components in a three-phase flow using gamma radiation technique, the existence of a scale layer has not been considered. The formed scale layer usually has a higher density in comparison to the fluid flow inside the oil pipeline, which can lead to high photon attenuation and, consequently, reduce the measuring precision of three-phase flow meter. The purpose of this study is to present an intelligent gamma radiation-based, nondestructive technique with the ability to measure volume fraction of gas, oil, and water components in the annular regime of a three-phase flow independent of the scale layer. Since, in this problem, there are several unknown parameters, such as gas, oil, and water components with different amounts and densities and scale layers with different thicknesses, it is not possible to measure the volume fraction using a conventional gamma radiation system. In this study, a system including a ${ }^{241} \mathrm{Am}-{ }^{133} \mathrm{Ba}$ dual energy source and two transmission detectors was used. The first detector was located diametrically in front of the source. For the second detector, at first, a sensitivity investigation was conducted in order to find the optimum position. The four extracted signals in both detectors (counts under photo peaks of both detectors) were used as inputs of neural network, and volume fractions of gas and oil components were utilized as the outputs. Using the proposed intelligent technique, volume fraction of each component was predicted independent of the barium sulfate scale layer, with a maximum MAE error of $3.66 \%$.
\end{abstract}

Keywords: annular regime; scale layer-independent; petroleum pipeline; volume fraction; dual energy technique

\section{Introduction}

Numerous applications for multiphase flow meters exist in the petrochemical and oil industries. For instance, there is a need to monitor multiphase flow continuously at some points. Some of these points include the gas-oil separator units and the wellhead collection lines. Monitoring at these points is of great value. The three-phase flow's volume fraction can be determined through several methodologies. One of the best methodologies is the gamma radiation-based technique, which is a nondestructive and reliable tool. Several studies have covered this area. One of the earliest studies was conducted in 1980, when Abouelwafa and Kendall introduced a method for metering three-phase flow. That is the dual-energy gamma-ray attenuation-based method [1]. In their study, Dong-hui et al. (2005) presented the dual-energy gamma-ray method. The method aimed to examine the volume fraction of various components on the multiphase pipe flow cross-section of gas-oil-water [2]. With the intent to measure the attenuation dose rate of the material, 
there was a need to design a data acquisition system and nuclear instruments. After designing the data acquisition system and the nuclear instruments, static tests followed. Oil-water-gas media has three phases. These phases were investigated to test the hypothesis that they effectively simulate different distributions of media volumetric fraction. The three phases were investigated when the oil-water-gas media was used in experimental vessels. During this investigation, the measurements of attenuation intensities were taken. There was also a study of the volumetric fraction's equations and the linear attenuation coefficients' arithmetic. When the attenuation equations were investigated for unexpected measurement error, the involvement of modified arithmetic was disclosed. Besides, the experimental research revealed that the system's accuracy was acceptable. In their study, Salgado et al. (2009) measured a three-phase flow volume fraction using the gamma radiation technique [3]. They used two radioactive sources whose energies were different. They also used three Nal detectors. In their estimation of the gas-oil-water's volume fraction, the researchers were aided by the artificial neural network (ANN). They considered several flow regimes in this process. The researchers replicated this methodology in 2010 to recognize the homogenous, stratified, and annular flow regime. They then estimated the water-gas-oil multiphase systems' volume fraction [4]. Hoffmann et al. (2011) measured phase fractions using a traversable gamma radiation-based instrument [5]. There was a need to ensure that the noisy measurements yielded relevant data. Therefore, the researchers had to be careful in their data analysis. In this regard, the researchers used the two-phase and single-phase flow calibration data and tested the three-phase flow data analysis technique against this data. The researchers found that the traversable gamma instrument's average density data was significantly related to the calibrated, stationary, single-energy gamma instrument's density measurements. However, more information was obtained from the traversable densitometer than from the single energy instrument. The rationale behind this is that it was possible to measure all the three phases' transient phase fraction over the pipeline's cross-section. By using this information, the flow pattern could be determined. Further studies in field of multiphase flow meters can be found in references [6-25].

According to the literature review, in the systems that used gamma radiation technique to determine the oil, water, and gas volume fraction, the existence of the scale layer's has not been considered. The scale layer forms gradually as mineral salts are deposited on the oil pipeline's inner surface. An example of such a layer is shown in Figure 1.

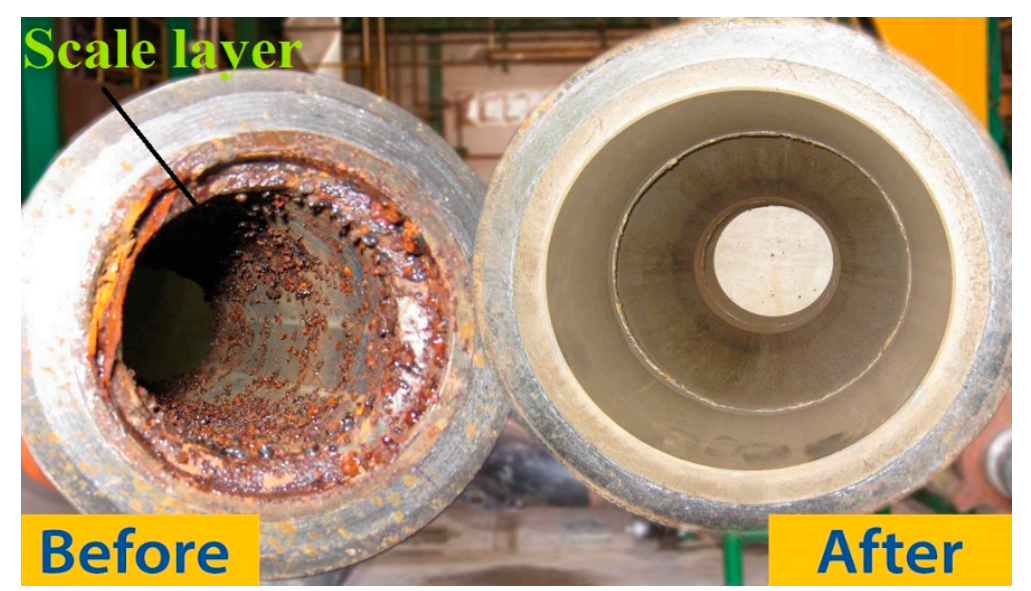

Figure 1. An oil pipeline before and after cleaning of the scale layer by chemical methods [26].

When the scale layer is compared to the fluid flow inside the oil pipeline, its density tends to be higher. In this regard, the three-phase flow meter's measuring precision can be reduced over time due to high photon attenuation that can occur due to the scale layer having a higher density. This study aims at presenting an intelligent gamma radiationbased system that can measure the oil, gas, and water components' volume fraction 
in a three-phase flow's annular regime independent of the scale layer. The article is structured as follows: Section 2 discusses the details of the proposed detection system and the implementation of the neural network. Section 3 reports the results of the neural network and calculates the accuracy of the designed neural networks. The last section provides both the summary and the conclusion.

\section{Materials and Methods}

\subsection{Radiation Based System}

Monte Carlo N Particle code (MCNP) [27] was implemented in the present investigation in order to model the radiation-based system. As pointed out in the abstract section, the aim of this investigation is to propose an intelligent, gamma radiation-based system with the ability of measuring volume fraction of gas, oil, and water components in annular regime of a three-phase flow independent of the scale layer. Since, in this problem, there are several unknown parameters, it is not possible to measure the volume fraction using a conventional gamma radiation system that includes one radiation source and one detector. To obtain more information from the fluid inside the pipe, a system including a dual energy source consisted of ${ }^{241} \mathrm{Am}$ and ${ }^{133} \mathrm{Ba}$ radioisotopes that emit photons with energies of 59 and $356 \mathrm{keV}$, respectively, and two NaI detectors for recording the transmitted photons, were used.

A steel pipe with internal radius and thickness of $10 \mathrm{~cm}$ and $0.5 \mathrm{~cm}$, respectively, was considered in this study. In order to model the scale layer, a cylindrical shell of barium sulfate $\left(\mathrm{BaSO}_{4}\right)$ with density of $4.5 \mathrm{~g} \cdot \mathrm{cm}^{-3}$ and different thicknesses in the range of $0-3 \mathrm{~cm}$, with a step of $0.5 \mathrm{~cm}$, was considered on the internal wall of the steel pipe.

Annular regime of a three-phase flow was modeled inside the pipe. Air, gas, oil, and water with densities of $0.00125,0.826$, and $1 \mathrm{~g} \cdot \mathrm{cm}^{-3}$ were utilized as gas, oil, and water phases, respectively. For each scale thickness, various volume fractions were simulated for each component (seven different scale thickness $\times 36$ different volume fractions $=$ totally 252 simulations were done).

As aforementioned, in this investigation, two $2.54 \mathrm{~cm} \times 2.54 \mathrm{~cm} \mathrm{NaI}$ detectors were applied to record the transmitted photons. Tally F8 was utilized in order to record photon spectra in both detectors. The first detector was positioned diametrically in front of the radioactive source (see Figure 2). For the second detector, at first, a sensitivity investigation was done in order to find the optimum position. In this regard, the center of the second detector was positioned in different orientation in the range of $5^{\circ}-11^{\circ}$, with a step of $1^{\circ}$, and transmitted photons were recorded. Orientation of $5^{\circ}$ was the minimum possible position for the second detector, because, at less than this orientation, the first and second detectors would interfere with each other. The reason for choosing orientation of $11^{\circ}$ as the maximum position was that, at more than this orientation, there would be no more transmitted photons through the pipe that carries on useful information about the three-phase flow to reach the detector. At each position, sensitivity of the second detector relative to gas phase and oil phase volume fraction changes was investigated for both registered counts of gamma radiations emitted from ${ }^{241} \mathrm{Am}$ and ${ }^{133} \mathrm{Ba}$ radioisotopes. For instance, calculation of sensitivity of registered counts under ${ }^{241} \mathrm{Am}$ photo peak in the second detector relative to gas phase changes is indicated in Equation (1). It is worth mentioning that the sensitivity was calculated using the registered counts for gas phase fractions of $10 \%$ and $80 \%$, which make the highest and lowest attenuation for photons.

$$
\text { Relative sensitivity }(\%)=\left(\frac{C_{g v f 80}-C_{g v f 10}}{C_{g v f 80}}\right) \times 100
$$

where, $C_{g v f 80}$ and $C_{g v f 10}$ refer to registered counts under ${ }^{241} \mathrm{Am}$ photo peak when the gas volume fraction is $80 \%$ and $10 \%$, respectively. The results of sensitivity investigations are shown in Figure 3. For all four cases, by increasing orientation angle of the second detector, sensitivity starts to increase until it reaches a maximum value at the angle of $7^{\circ}$ and then 
it gradually decreases. Based on the acquired results, it could be deduced that $7^{\circ}$ is the optimal orientation angle for the second detector.

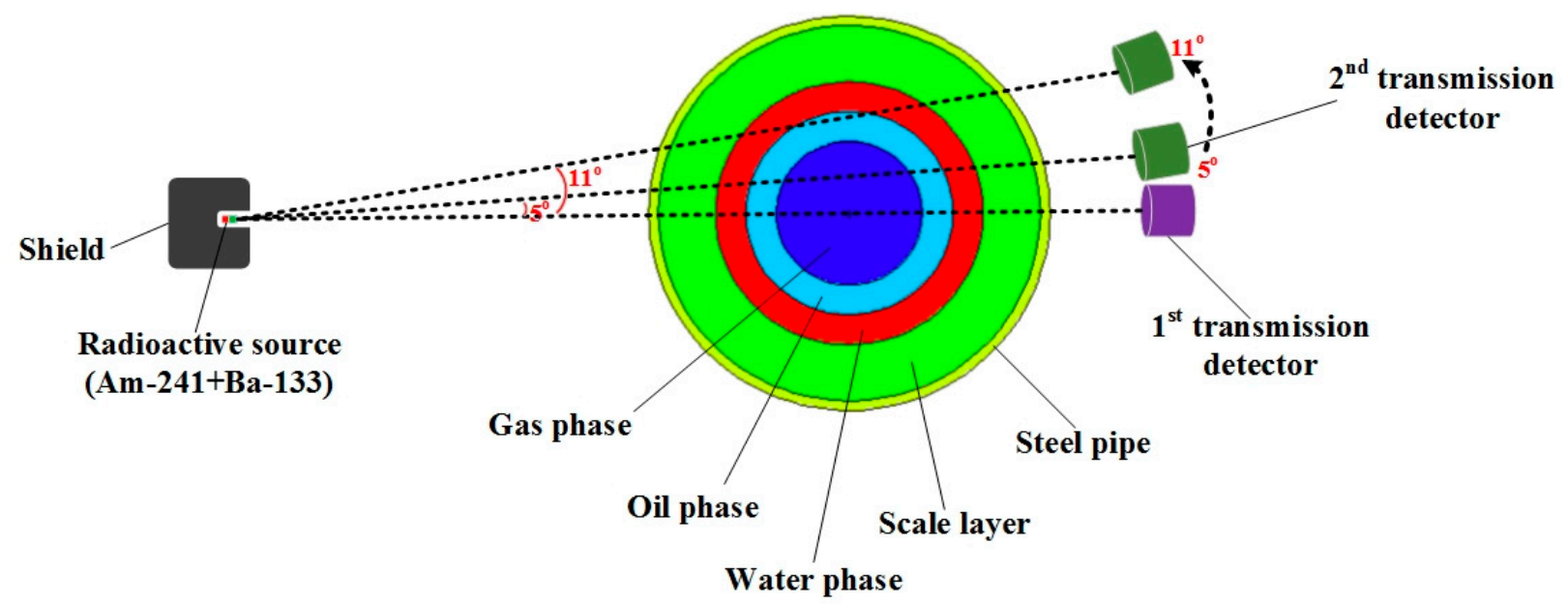

Figure 2. Investigation of optimum position for the second detector in the proposed system.

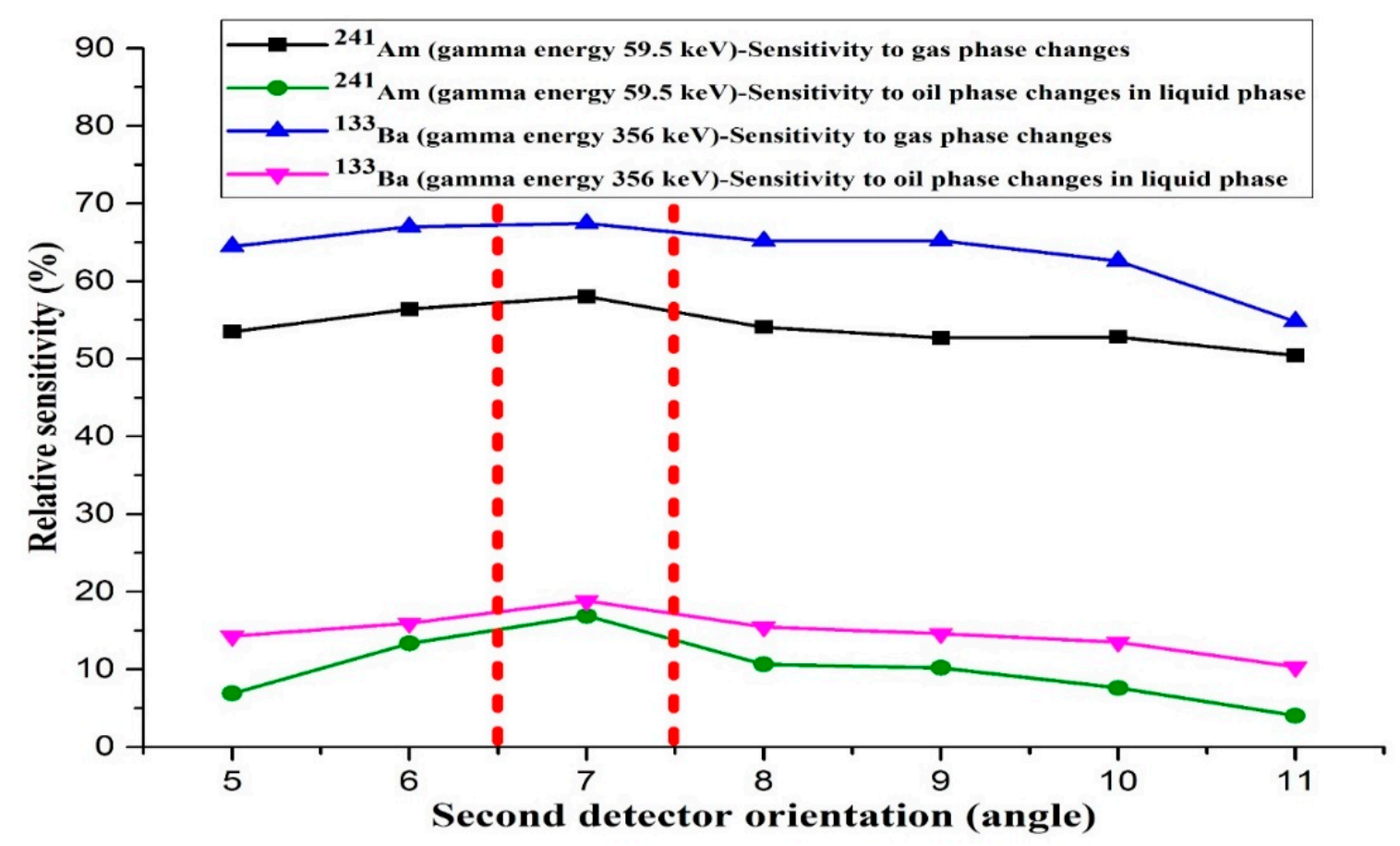

Figure 3. Sensitivity investigations results to find optimum position for the second detector.

It is worth mentioning that the simulated configuration in this work, especially the performance of the detectors, has been validated in our previous study using some experiments [28]. The corresponding experimental setup can be seen in Figure 4. A geometry identical to the experimental setup was simulated using MCNP code, and then the registered counts in both detectors were compared with the experimental ones. Calibrations of the gamma attenuation-based devices used for measuring the three-phase flow characteristics are usually done for three different extreme cases when the pipe is completely filled by gas, oil, and water. In the present study, a detection system the same as the validated one in our previous work was modeled. However, in the present study, a gas-oil-water three-phase flow was modeled instead of a two-phase flow. 


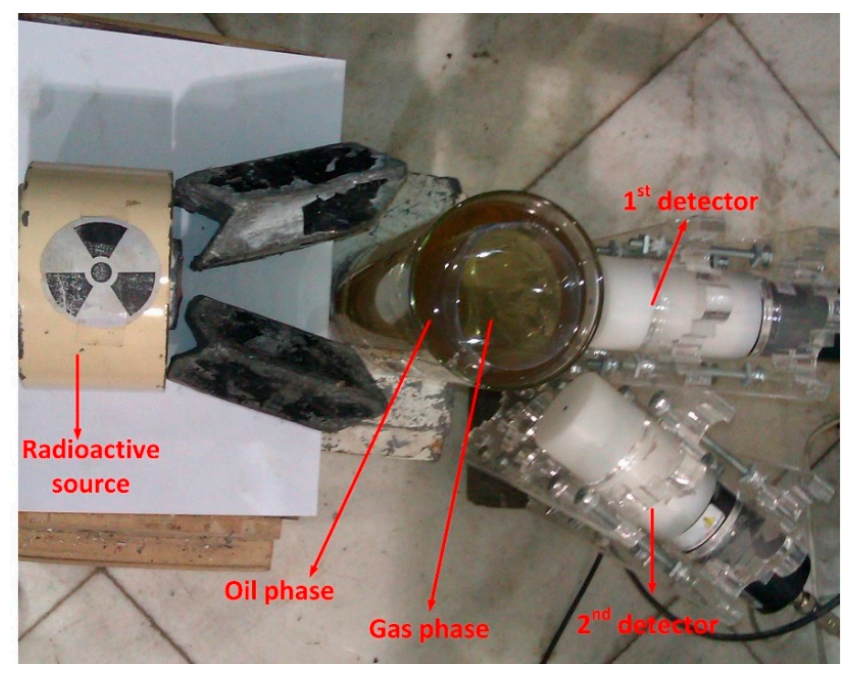

Figure 4. Experimental setup including $2 \mathrm{NaI}$ detectors and one radioactive source [28].

\subsection{Artificial Intelligence}

In recent years, it has been proved that artificial intelligence can be implemented as a powerful tool for various engineering applications [29-65]. There are several kinds of ANNs, in which multilayer perceptron (MLP) is the most well-known kind of them. This kind of ANN has a good ability for regression and classification. This network is constructed from at least three layers of neurons: The input layer, the hidden layer (or hidden layers), and the output layer. There are different techniques to calculate the biases and weights of this mathematical network, of which Levenberg Marquardt (LM) is most well-known algorithm in this regard. In the present investigation, two different MLP-LM networks with four inputs and one output were considered. Four features were extracted from the recorded spectra in the detectors and were considered as MLP-LM inputs. The procedure of obtaining gas, oil, and water volume fraction percentages independent of scale layer thickness is indicated in Figure 5. The trained networks can estimate the percentages of gas and oil volume fraction based on input signals independent of scale layer thickness, correctly.

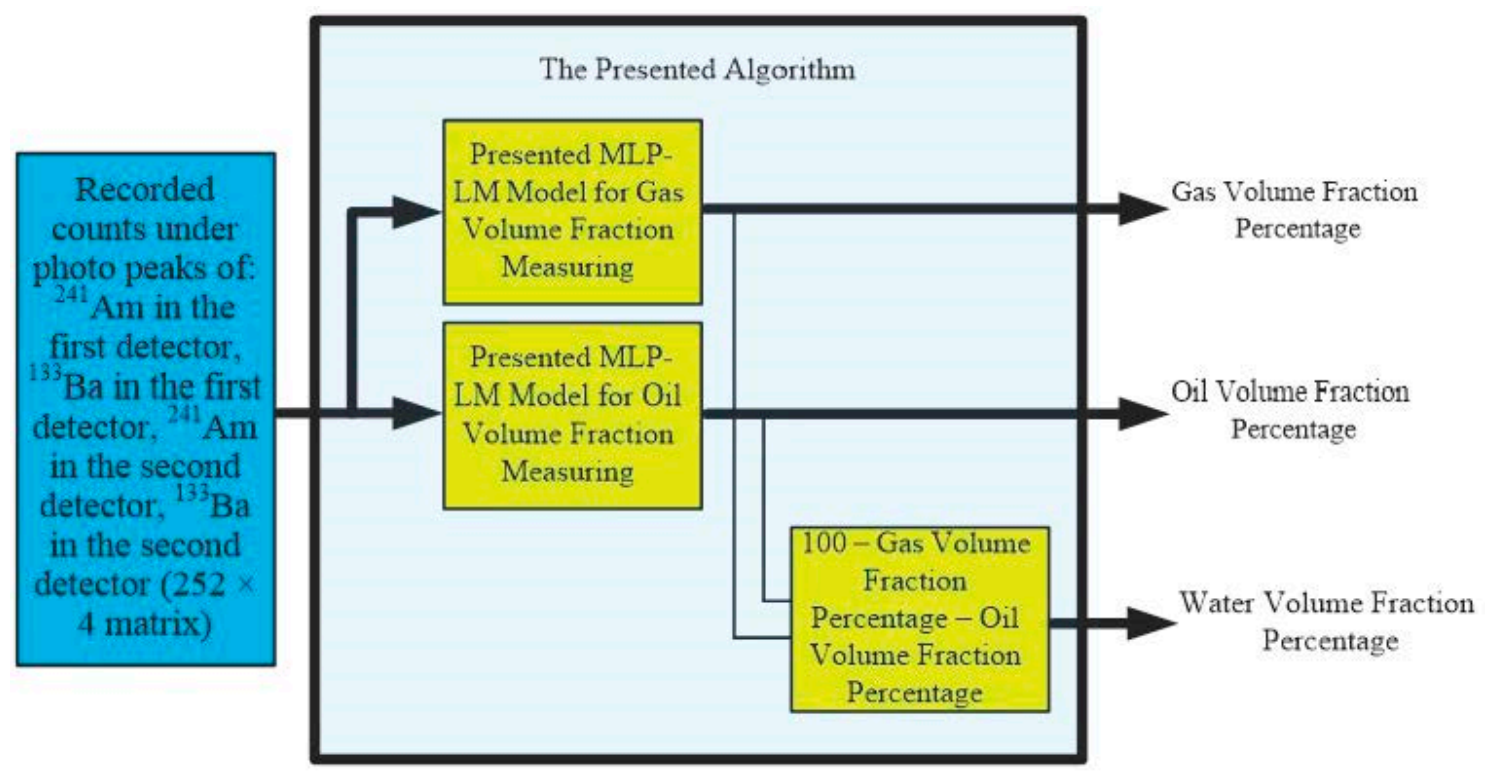

Figure 5. The procedure of obtaining gas, oil, and water volume fraction percentage in a three-phase flow independent of scale layer thickness. 
A total of 252 different cases were simulated using MCNPX code; 177 cases were implemented for training the network, and 75 cases were used for testing the efficiency of presented MLP-LM. In order to obtain the optimum structure of proposed networks, different structures with various number of layers, neurons in each layer, epochs, and different activation functions were tested. For this purpose, different loops were defined, and, with trial and error, the optimum architecture was found. The mentioned algorithm is:

(1) The data set, counters, and error are defined.

(2) The data set is normalized.

(3) The parameters initial values are set.

(4) Several loops are created.

(5) Different number of layers, neurons in each layer, epochs, and different activation functions are tested.

(6) The efficiency of each network is checked.

(7) The best network with lowest error is saved.

The best structure of presented MLP-LM model for gas volume fraction measuring has one hidden layer consists of 9 neurons. The number of epochs was 685. The best structure of presented MLP-LM model for oil volume fraction measuring has one hidden layer consists of 10 neurons. The number of epochs was 750. Architectures of the ANN models were shown in Figure 6.

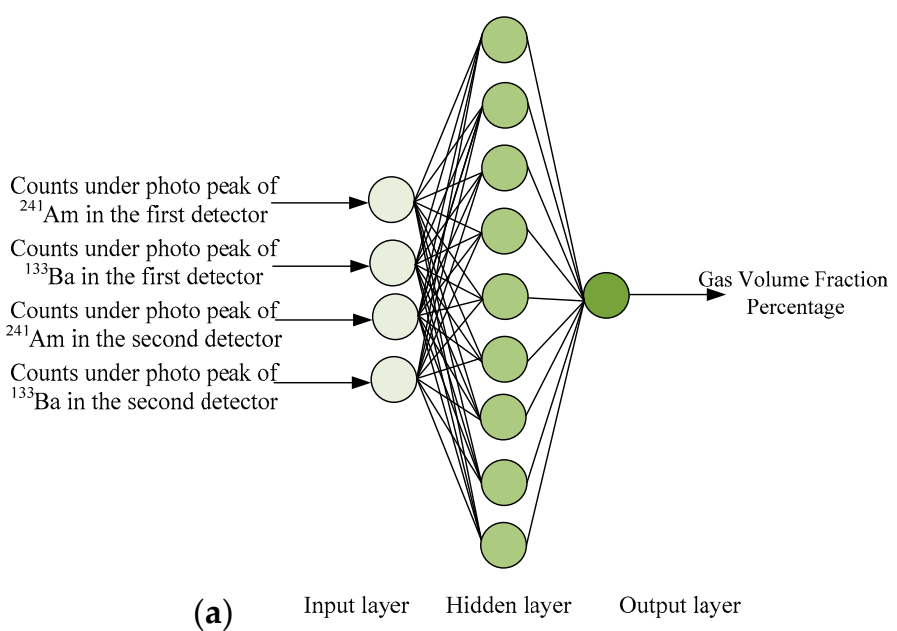

(a)

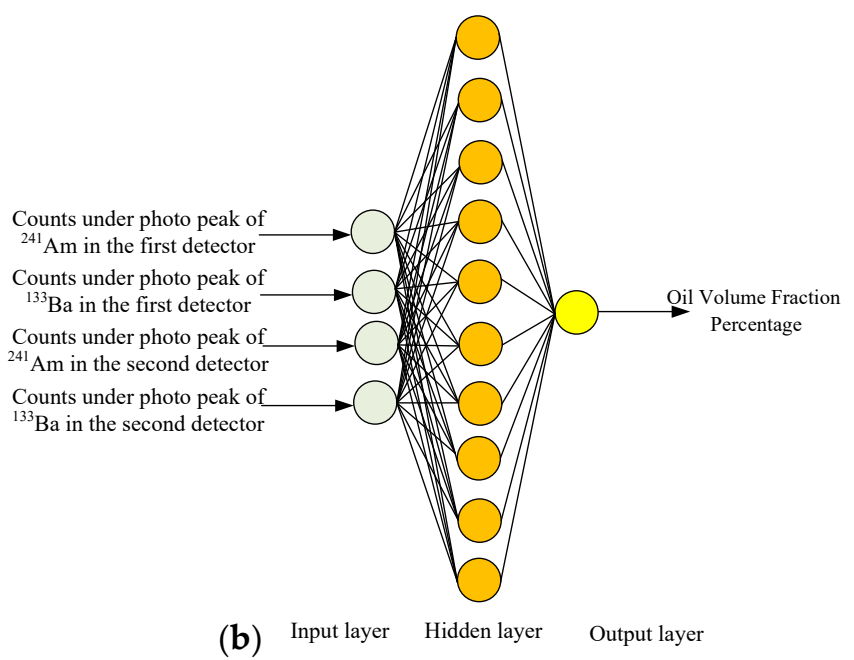

(b) Input layer Hidden layer Output layer

Figure 6. Architectures of presented MLP-LM models (a) for gas volume fraction measuring (b) for oil volume fraction measuring.

The mathematical equations for the first MLP-LM model are as follows. The input to the neuron $\mathbf{m}$ in the hidden layer is given by:

$$
\eta_{m}=\sum_{u=1}^{4}\left(X_{u} W_{u m}\right)+b_{m} \quad m=1,2, \ldots, 9
$$

The output from $m$ th neuron of the hidden layer is given by:

$$
U_{m}=f\left(\sum_{u=1}^{4}\left(X_{u} W_{u m}\right)+b_{m}\right) \quad m=1,2, \ldots, 9
$$

The output of the neuron in the output layer is given by:

$$
O=\sum_{u=1}^{9}\left(U_{u} W_{u}\right)+b
$$


where $X$ is the input vector, $b$ is the bias term, $W$ is the weighting factor, and $\mathrm{f}$ is the activation function of the hidden layer.

\section{Results and Discussions}

After finding optimum positions for the detectors, orientation angle of $0^{\circ}$ for the first detector and $7^{\circ}$ for the second detector, counts under photo peaks of ${ }^{241} \mathrm{Am}$ and ${ }^{133} \mathrm{Ba}$ radioisotopes were recorded in both detectors for different scale layer thicknesses and volume fractions. Ternary contour plots of the recorded counts in both detectors for different volume fractions when the scale thickness is 0 and $3 \mathrm{~cm}$, are shown in Figures 7-10. Comparing Figures 7 and 8 that correspond to the recorded counts in the first detector for ${ }^{241} \mathrm{Am}$ and ${ }^{133} \mathrm{Ba}$ radioisotopes, respectively, it can be said that dynamic range of registered counts relative to changes of gas volume fraction, or, better to say, sensitivity, for ${ }^{133} \mathrm{Ba}$ is more than ${ }^{241} \mathrm{Am}$. A same response is also observed for the second detector. Comparing Figure $7 a, b$, it could be observed that, when scale layer is 0 , sensitivity of detector relative to changes of gas, oil, and water components is much more than when the scale thickness is 3. In other words, by increasing thickness of scale layer, somehow information about the flow of inside the pipe starts fading. This manner can be also seen for both detectors and radioisotopes. Comparing Figures 7a and 9a, it can be observed that sensitivity of the second detector relative to changes of volume fractions is a little bit more than the first detector.

Regression diagrams of actual data and predicted data using presented MLP-LM models are shown in Figures 11 and 12. In Table 1, data number, scale layer thickness, actual outputs, and measured outputs for test data set are tabulated.

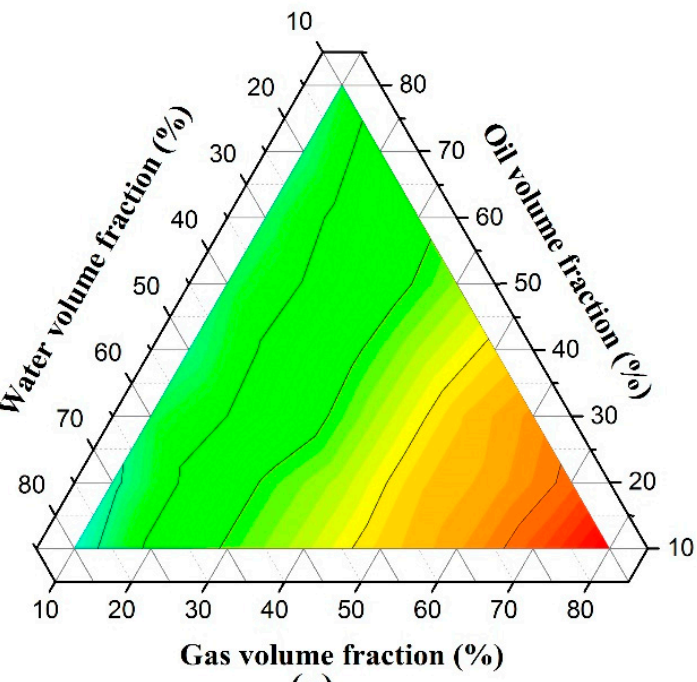

(a)

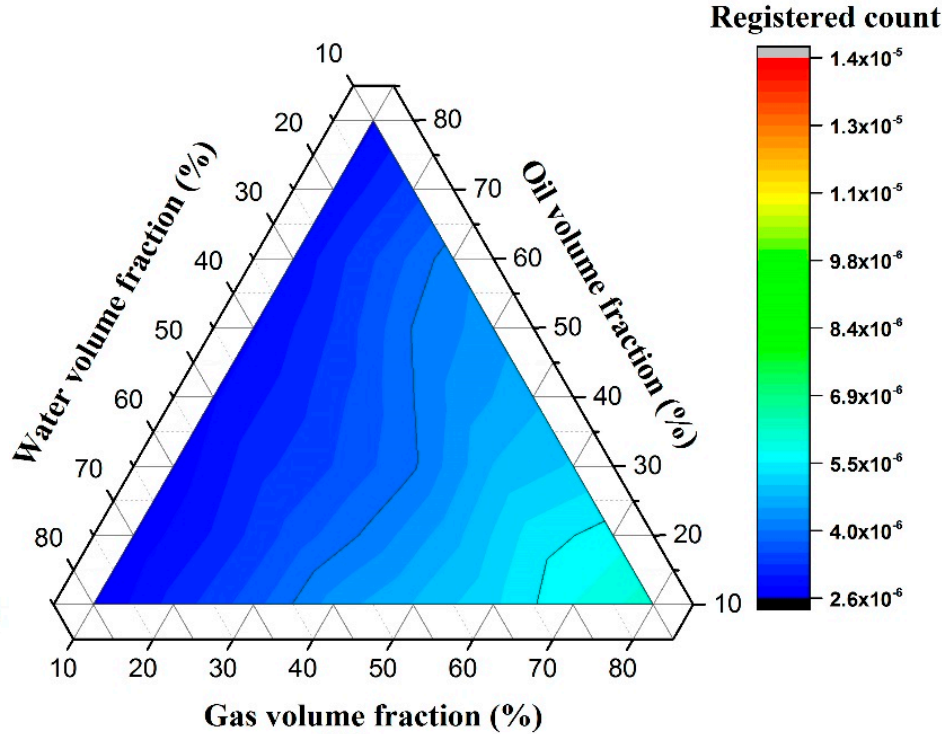

(b)

Figure 7. Recorded counts under photo peaks of ${ }^{241} \mathrm{Am}$ in the first detector versus gas, oil, and water volume fraction: (a) scale thickness is 0 , (b) scale thickness is $3 \mathrm{~cm}$.

Mean Absolute Error (MAE) and Root Mean Square Error (RMSE) of presented metering system were calculated using Equations (5) and (6).

$$
\begin{gathered}
\text { MAE }=\frac{1}{N} \sum_{i=1}^{Z} \mid X_{i}(\text { Actual })-X_{i}(\text { Measured }) \mid \\
\text { RMSE }=\left[\frac{\sum_{i=1}^{N}\left(\left(X_{i}(\text { Actual })-X_{i}(\text { Measured })\right)^{2}\right.}{N}\right]^{0.5}
\end{gathered}
$$


where $N, X_{i}\left(\right.$ Actual), and $X_{i}$ (Measured) are the data number, real values, and estimated values, respectively. Performance criteria of the developed models were tabulated in Table 2 using Equations (5) and (6).

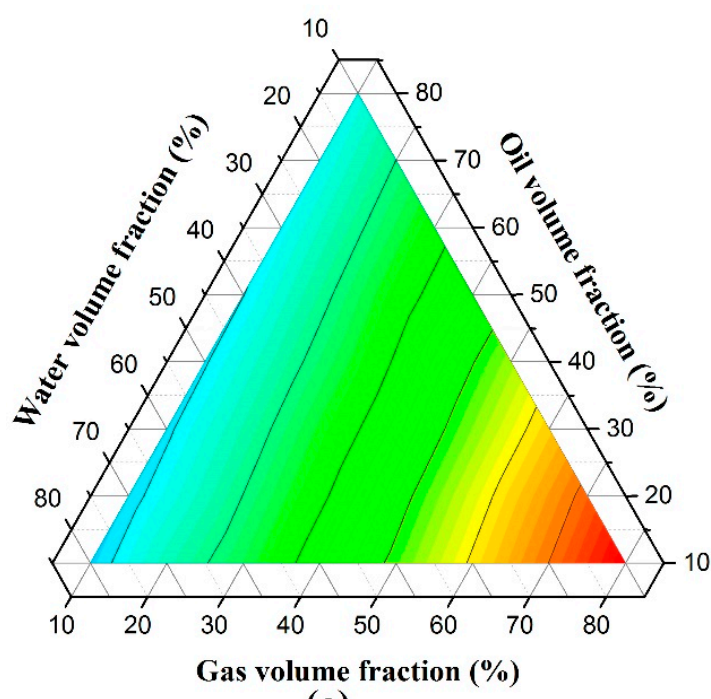

(a)

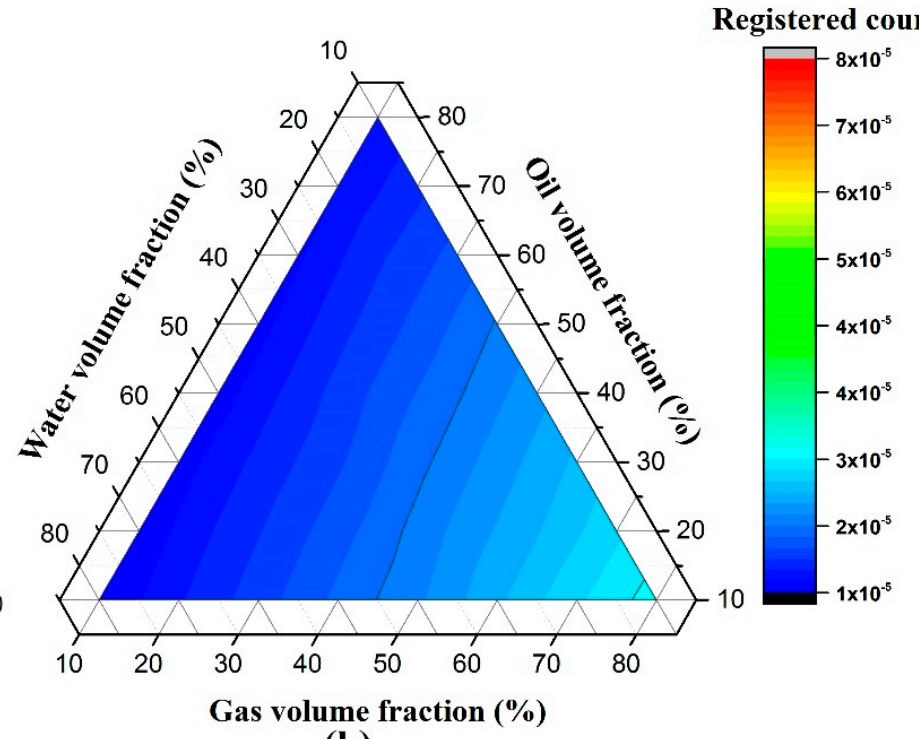

(b)

Figure 8. Recorded counts under photo peaks of ${ }^{133} \mathrm{Ba}$ in the first detector versus gas, oil, and water volume fraction: (a) scale thickness is $0,(\mathbf{b})$ scale thickness is $3 \mathrm{~cm}$.

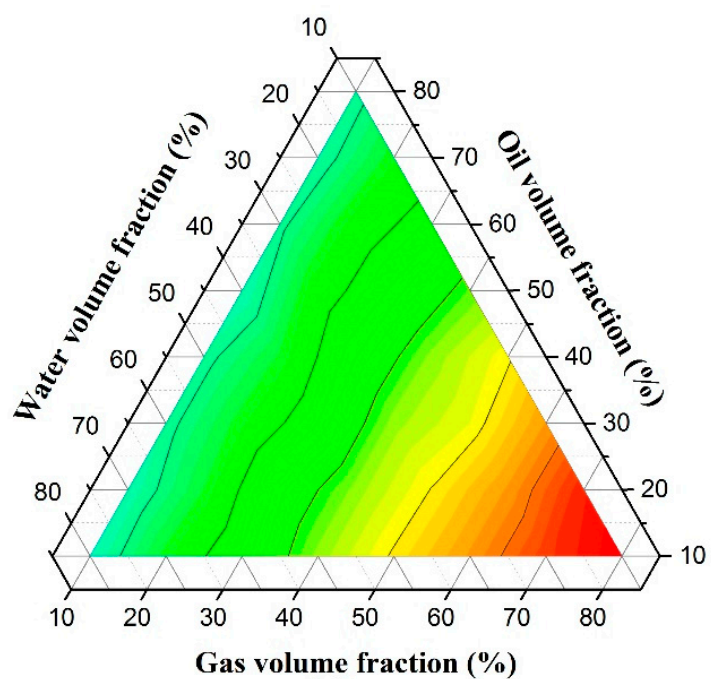

(a)

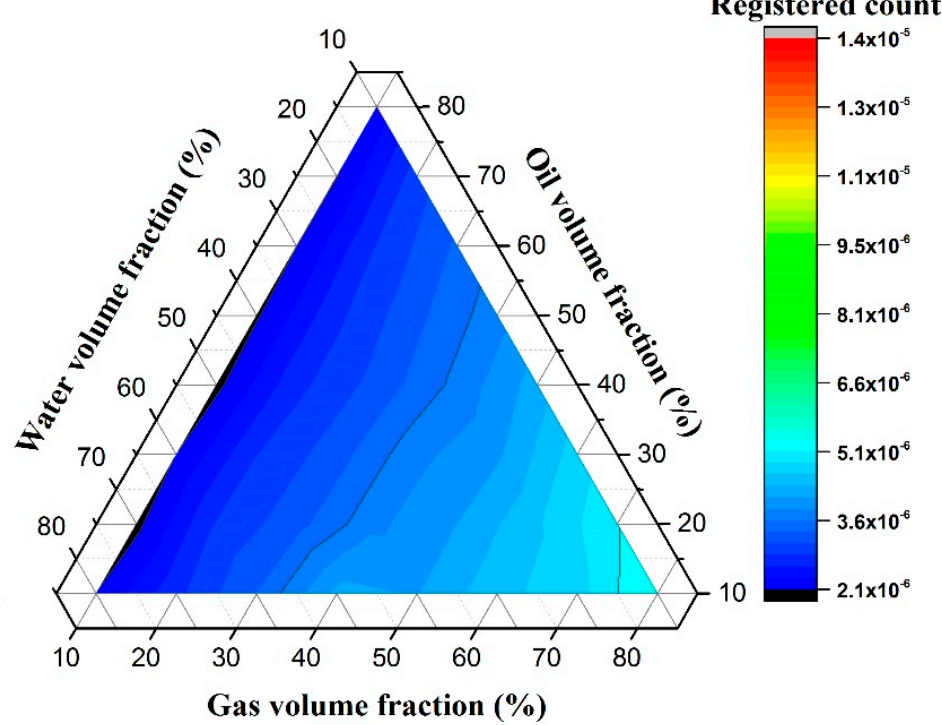

(b)

Figure 9. Recorded counts under photo peaks of ${ }^{241} \mathrm{Am}$ in the second detector versus gas, oil, and water volume fraction: (a) scale thickness is $0,(\mathbf{b})$ scale thickness is $3 \mathrm{~cm}$.

It can be found from the obtained errors that the presented gauging system is reliable. This novel meter could be used in different industries for metering volume fraction of each phase independent of scale layer thickness. Radioisotope sources, detectors type, detectors position, extracted features from output signals, used data analysis algorithms and ANN architectures were selected appropriately in order to achieve the optimum performance for the proposed system. 


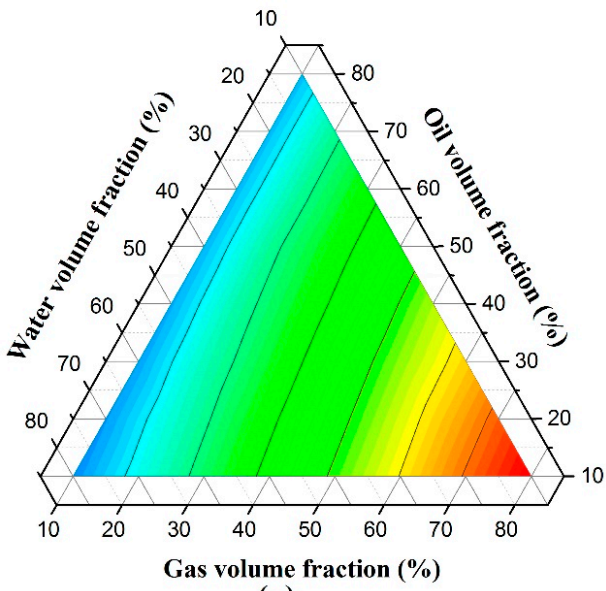

(a)

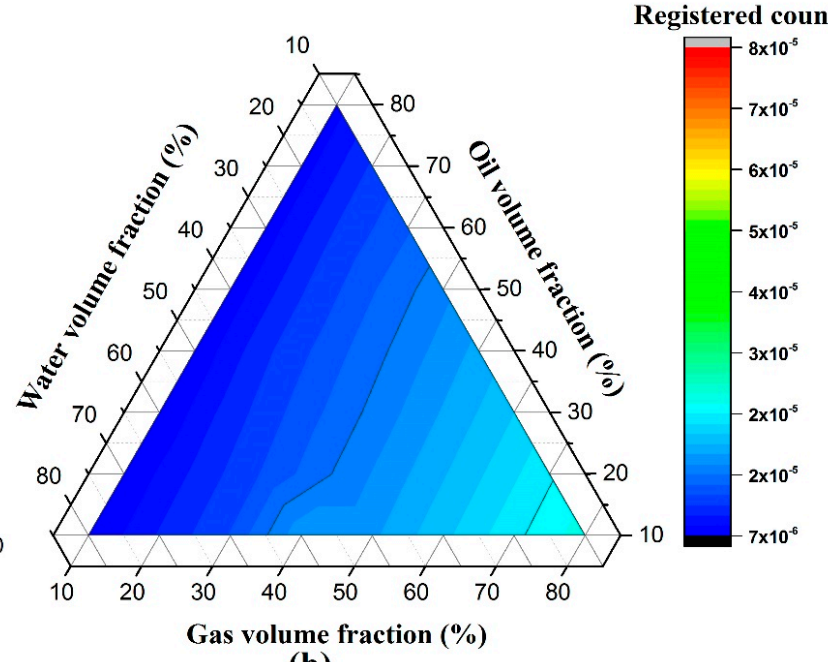

(b)

Figure 10. Recorded counts under photo peaks of ${ }^{133} \mathrm{Ba}$ in the second detector versus gas, oil, and water volume fraction: (a) scale thickness is 0 , (b) scale thickness is $3 \mathrm{~cm}$.

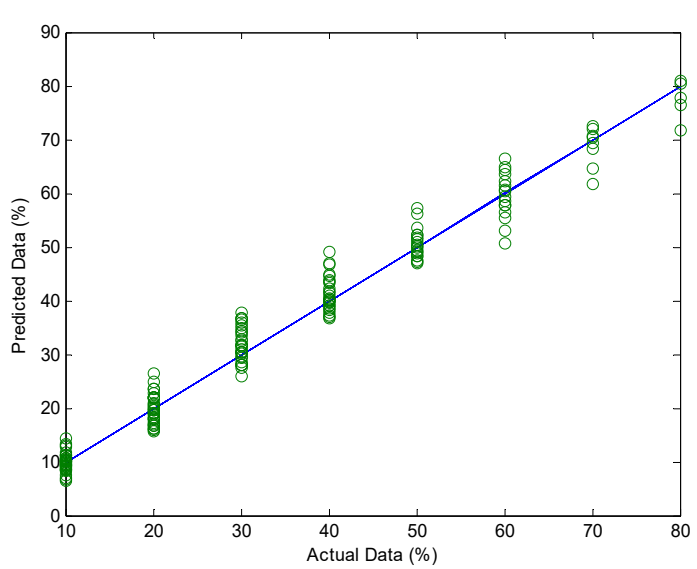

(a)

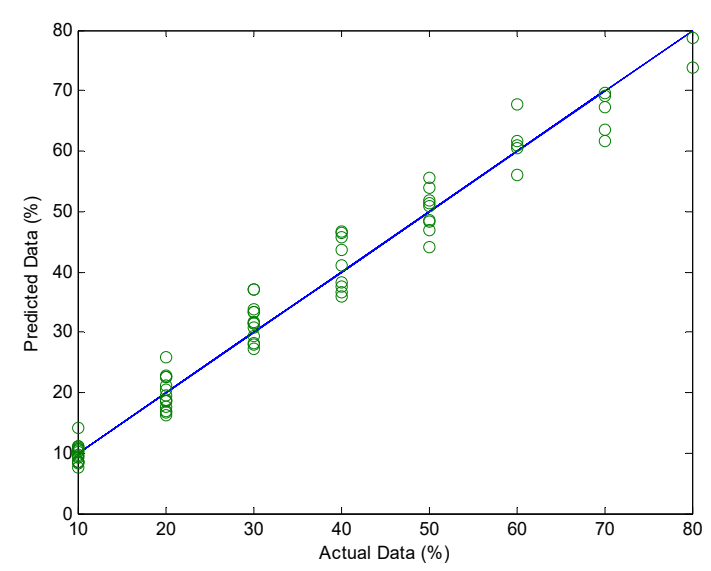

(b)

Figure 11. Regression diagrams of first model results (gas volume fraction) for (a) train data (b) test data.

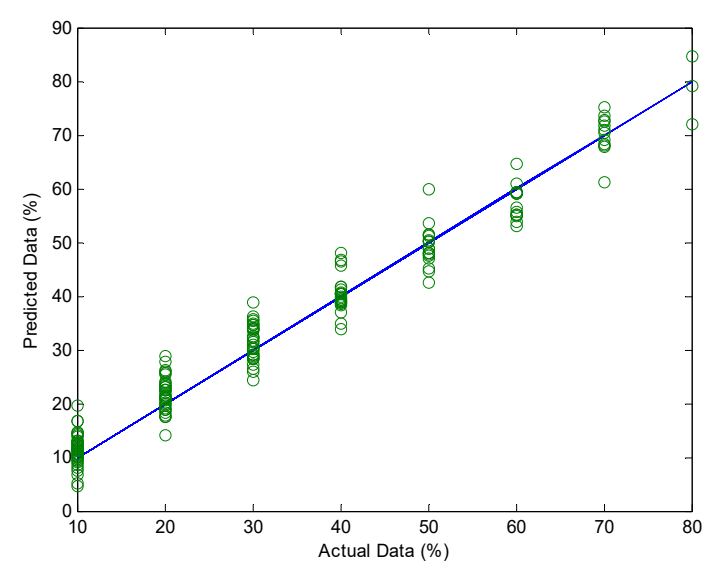

(a)

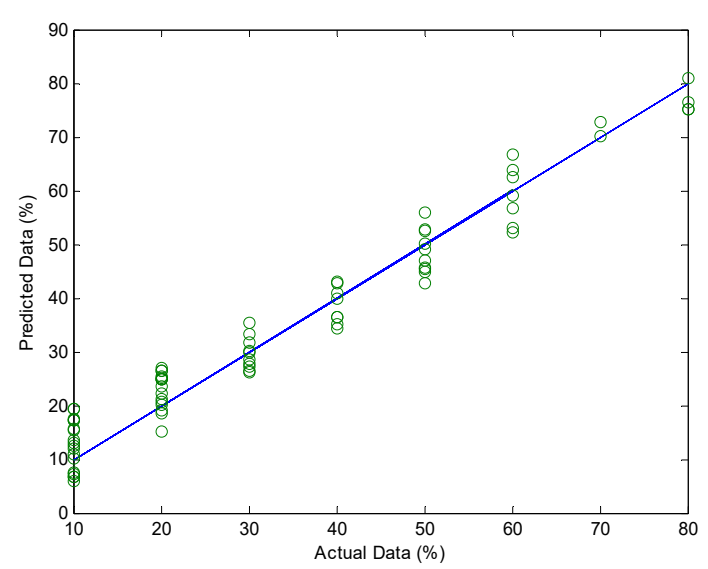

(b)

Figure 12. Regression diagrams of second model results (oil volume fraction) for (a) train data (b) test data. 
Table 1. The test data with predicted values.

\begin{tabular}{|c|c|c|c|c|c|c|c|c|c|c|c|}
\hline Data Number & $\begin{array}{l}\text { Scale Layer } \\
\text { Thickness }\end{array}$ & $\begin{array}{c}\text { Actual } \\
\text { Percentage of } \\
\text { Gas Volume } \\
\text { Fraction }\end{array}$ & $\begin{array}{l}\text { Predicted } \\
\text { Percentage of } \\
\text { Gas Volume } \\
\text { Fraction }\end{array}$ & $\begin{array}{c}\text { Actual } \\
\text { Percentage of } \\
\text { Oil Volume } \\
\text { Fraction }\end{array}$ & $\begin{array}{c}\text { Predicted } \\
\text { Percentage of } \\
\text { Oil Volume } \\
\text { Fraction }\end{array}$ & Data Number & $\begin{array}{c}\text { Scale Layer } \\
\text { Thickness }\end{array}$ & $\begin{array}{c}\text { Actual } \\
\text { Percentage of } \\
\text { Gas Volume } \\
\text { Fraction }\end{array}$ & $\begin{array}{l}\text { Predicted } \\
\text { Percentage of } \\
\text { Gas Volume } \\
\text { Fraction }\end{array}$ & $\begin{array}{l}\text { Actual } \\
\text { Percentage of } \\
\text { Oil Volume } \\
\text { Fraction }\end{array}$ & $\begin{array}{c}\text { Predicted } \\
\text { Percentage of } \\
\text { Oil Volume } \\
\text { Fraction } \\
\end{array}$ \\
\hline 1 & 0 & 10 & 10.192 & 30 & 33.188 & 39 & 1.5 & 30 & 31.776 & 20 & 15.131 \\
\hline 2 & 0 & 10 & 9.1929 & 70 & 72.778 & 40 & 1.5 & 30 & 33.395 & 50 & 42.774 \\
\hline 3 & 0 & 20 & 18.589 & 20 & 23.656 & 41 & 1.5 & 40 & 38.145 & 20 & 24.954 \\
\hline 4 & 0 & 20 & 22.769 & 50 & 45.377 & 42 & 1.5 & 50 & 44.139 & 10 & 19.463 \\
\hline 5 & 0 & 30 & 27.957 & 20 & 21.208 & 43 & 1.5 & 60 & 61.639 & 10 & 10.063 \\
\hline 6 & 0 & 30 & 27.197 & 50 & 44.794 & 44 & 1.5 & 70 & 69.562 & 10 & 17.143 \\
\hline 7 & 0 & 40 & 40.997 & 20 & 26.426 & 45 & 2 & 10 & 9.568 & 10 & 13.678 \\
\hline 8 & 0 & 40 & 46.476 & 50 & 46.974 & 46 & 2 & 10 & 9.3796 & 50 & 52.381 \\
\hline 9 & 0 & 50 & 54.003 & 40 & 40.954 & 47 & 2 & 10 & 11.105 & 80 & 80.937 \\
\hline 10 & 0 & 60 & 60.570 & 30 & 30.223 & 48 & 2 & 20 & 22.548 & 30 & 26.564 \\
\hline 11 & 0 & 80 & 78.644 & 10 & 17.264 & 49 & 2 & 20 & 25.880 & 60 & 53.048 \\
\hline 12 & 0.5 & 10 & 14.223 & 30 & 35.266 & 50 & 2 & 30 & 37.023 & 20 & 26.569 \\
\hline 13 & 0.5 & 10 & 14.259 & 60 & 63.838 & 51 & 2 & 30 & 33.899 & 50 & 45.598 \\
\hline 14 & 0.5 & 20 & 16.300 & 20 & 25.508 & 52 & 2 & 40 & 45.734 & 30 & 27.702 \\
\hline 15 & 0.5 & 20 & 18.683 & 60 & 62.395 & 53 & 2 & 50 & 55.656 & 20 & 19.188 \\
\hline 16 & 0.5 & 30 & 29.442 & 30 & 29.886 & 54 & 2 & 60 & 67.743 & 10 & 10.936 \\
\hline 17 & 0.5 & 30 & 30.865 & 60 & 59.076 & 55 & 2 & 70 & 67.136 & 10 & 6.609 \\
\hline 18 & 0.5 & 40 & 46.686 & 30 & 26.175 & 56 & 2.5 & 10 & 10.469 & 20 & 22.249 \\
\hline 21 & 0.5 & 70 & 69.221 & 10 & 12.063 & 59 & 2.5 & 20 & 19.480 & 40 & 42.727 \\
\hline 22 & 1 & 10 & 10.599 & 10 & 15.606 & 60 & 2.5 & 30 & 37.115 & 10 & 13.023 \\
\hline 23 & 1 & 10 & 9.643 & 40 & 39.935 & 61 & 2.5 & 30 & 33.332 & 40 & 42.970 \\
\hline 24 & 1 & 10 & 11.224 & 80 & 76.384 & 62 & 2.5 & 40 & 43.650 & 20 & 18.483 \\
\hline 25 & 1 & 20 & 16.727 & 30 & 27.304 & 63 & 2.5 & 50 & 50.924 & 10 & 6.802 \\
\hline 26 & 1 & 20 & 17.615 & 60 & 56.777 & 64 & 2.5 & 60 & 61.051 & 10 & 17.548 \\
\hline 27 & 1 & 30 & 31.423 & 20 & 25.014 & 65 & 2.5 & 70 & 61.640 & 10 & 12.625 \\
\hline 28 & 1 & 30 & 28.196 & 50 & 50.101 & 66 & 3 & 10 & 8.257 & 20 & 24.801 \\
\hline 29 & 1 & 40 & 35.962 & 20 & 24.818 & 67 & 3 & 10 & 8.638 & 50 & 55.815 \\
\hline 30 & 1 & 40 & 37.449 & 50 & 48.968 & 68 & 3 & 10 & 10.566 & 80 & 75.169 \\
\hline 31 & 1 & 50 & 48.608 & 30 & 31.725 & 69 & 3 & 20 & 21.072 & 40 & 36.381 \\
\hline 32 & 1 & 60 & 56.010 & 20 & 20.542 & 70 & 3 & 20 & 22.616 & 70 & 70.018 \\
\hline 33 & 1 & 80 & 73.836 & 10 & 5.888 & 71 & 3 & 30 & 31.506 & 40 & 35.196 \\
\hline 34 & 1.5 & 10 & 10.833 & 20 & 20.221 & 72 & 3 & 40 & 36.545 & 20 & 27.044 \\
\hline 35 & 1.5 & 10 & 7.667 & 50 & 52.823 & 73 & 3 & 50 & 51.333 & 10 & 7.174 \\
\hline 36 & 1.5 & 10 & 8.459 & 80 & 75.090 & 74 & 3 & 50 & 48.273 & 40 & 36.407 \\
\hline 37 & 1.5 & 20 & 18.903 & 30 & 28.645 & 75 & 3 & 70 & 63.588 & 10 & 7.416 \\
\hline 38 & 1.5 & 20 & 20.442 & 60 & 52.318 & & & & & & \\
\hline
\end{tabular}


Table 2. Performance criteria of the developed model.

\begin{tabular}{ccccc}
\hline \multirow{2}{*}{ Output } & \multicolumn{2}{c}{ RMSE } & \multicolumn{2}{c}{ MAE } \\
\cline { 2 - 5 } & Train & Test & Train & Test \\
\hline Gas Volume Fraction Percentage & 3.0956 & 3.3362 & 2.3266 & 2.6198 \\
\hline Oil Volume Fraction Percentage & 3.5757 & 4.3268 & 2.7662 & 3.6579 \\
\hline
\end{tabular}

\section{Conclusions}

In the present investigation, a novel and optimized radiation-based gauge, including two detectors and a dual energy source, was presented to measure volume fraction of gas, oil, and water components in annular regime of a three-phase flow independent of the scale layer. Position of the second detector was optimized. The percentages of gas, oil, and water volume fractions were measured independent of the barium sulfate scale layer. In fact, the presented measuring system can be used in different pipes with different thicknesses of scale layer. All the required data for modeling the presented system was achieved using MCNPX code. In order to model the metering system using MATLAB software, two different ANNs with four inputs and one output were considered. Recorded counts under photo peaks of ${ }^{241} \mathrm{Am}$ and ${ }^{133} \mathrm{Ba}$ were applied to both ANN models, as $252 \times 4$ input matrix and gas and oil volume fraction percentages were considered as the first and second ANN model outputs, respectively. The architectures of both ANNs were optimized using a presented algorithm. The dataset was divided to train set and test set. The accuracy of models was confirmed by good agreement of actual data and measured data in both sets. Finally, the volume fraction percentages were predicted with the RMSE of less than 4.33 and independent of scale layer.

Author Contributions: Conceptualization, E.N. and O.T.; Software, A.S.A., E.N., O.T. and E.M.K.; Writing-Review and Editing, A.S.A., E.N., O.T. and E.M.K.; Funding acquisition, A.S.A. and O.T. All authors have read and agreed to the published version of the manuscript.

Funding: This work was funded by the Deanship of Scientific Research (DSR), King Abdulaziz University, Jeddah, under grant No. (D-464-135-1441). The authors, therefore, gratefully acknowledge the DSR technical and financial support.

Institutional Review Board Statement: Not applicable.

Informed Consent Statement: Not applicable.

Data Availability Statement: Data is contained within the article.

Conflicts of Interest: The authors declare no conflict of interest.

\section{References}

1. Abouelwafa, M.; Kendall, E. The measurement of component ratios in multiphase systems using alpha-ray attenuation. J. Phys. E Sci. Instrum. 1980, 13, 341. [CrossRef]

2. Li, D.; Wu, Y.; Li, Z.; Zhong, X. Volumetric fraction measurement in oil-water-gas multiphase flow with dual energy gamma-ray system. J. Zhejiang Univ. Sci. A 2005, 6, 1405-1411.

3. Salgado, C.M.; Brandão, L.E.; Schirru, R.; Pereira, C.M.; da Silva, A.X.; Ramos, R. Prediction of volume fractions in three-phase flows using nuclear technique and artificial neural network. Appl. Radiat. Isot. 2009, 67, 1812-1818. [CrossRef]

4. Salgado, C.M.; Pereira, C.M.; Schirru, R.; Brandão, L.E. Flow regime identification and volume fraction prediction in multiphase flows by means of gamma-ray attenuation and artificial neural networks. Prog. Nucl. Energy 2010, 52, 555-562. [CrossRef]

5. Hoffmann, R.; Johnson, G.W. Measuring phase distribution in high pressure three-phase flow using gamma densitometry. Flow Meas. Instrum. 2011, 22, 351-359. [CrossRef]

6. Karami, A.; Roshani, G.H.; Khazaei, A.; Nazemi, E.; Fallahi, M. Investigation of different sources in order to optimize the nuclear metering system of gas-oil-water annular flows. Neural Comput. Appl. 2020, 32, 3619-3631. [CrossRef]

7. Meric, I.; Johansen, G.A.; Mattingly, J.; Gardner, R. On the ill-conditioning of the multiphase flow measurement by prompt gamma-ray neutron activation analysis. Radiat. Phys. Chem. 2014, 95, 401-404. [CrossRef]

8. Oliveira, D.F.; Nascimento, J.R.; Marinho, C.A.; Lopes, R.T. Gamma transmission system for detection of scale in oil exploration pipelines. Nucl. Instrum. Methods Phys. Res. Sect. A Accel. Spectrometers Detect. Assoc. Equip. 2015, 784, 616-620. [CrossRef] 
9. Hanus, R.; Zych, M.; Mosorov, V.; Golijanek-Jędrzejczyk, A.; Jaszczur, M.; Andruszkiewicz, A. Evaluation of liquid-gas flow in pipeline using gamma-ray absorption technique and advanced signal processing. Metrol. Meas. Syst. 2021, 28, 145-159.

10. Roshani, M.; Phan, G.T.; Ali, P.J.M.; Roshani, G.H.; Hanus, R.; Duong, T.; Corniani, E.; Nazemi, E.; Kalmoun, E.M. Evaluation of flow pattern recognition and void fraction measurement in two phase flow independent of oil pipeline's scale layer thickness. Alex. Eng. J. 2021, 60, 1955-1966. [CrossRef]

11. Nazemi, E.; Feghhi, S.; Roshani, G.; Setayeshi, S.; Peyvandi, R.G. A radiation-based hydrocarbon two-phase flow meter for estimating of phase fraction independent of liquid phase density in stratified regime. Flow Meas. Instrum. 2015, 46, 25-32. [CrossRef]

12. Nazemi, E.; Feghhi, S.; Roshani, G.; Peyvandi, R.G.; Setayeshi, S. Precise Void Fraction Measurement in Two-phase Flows Independent of the Flow Regime Using Gamma-ray Attenuation. Nucl. Eng. Technol. 2016, 48, 64-71. [CrossRef]

13. Vlasák, P.; Chára, Z.; Matoušek, V.; Konfršt, J.; Kesely, M. Experimental investigation of fine-grained settling slurry flow behaviour in inclined pipe sections. J. Hydrol. Hydromech. 2019, 67, 113-120. [CrossRef]

14. Roshani, G.H.; Nazemi, E.; Roshani, M.M. Flow regime independent volume fraction estimation in three-phase flows using dual-energy broad beam technique and artificial neural network. Neural Comput. Appl. 2016, 28, 1265-1274. [CrossRef]

15. El Abd, A. Intercomparison of gamma ray scattering and transmission techniques for gas volume fraction measurements in two phase pipe flow. Nucl. Instrum. Methods Phys. Res. Sect. A 2014, 735, 260-266. [CrossRef]

16. Roshani, G.H.; Roshani, S.; Nazemi, E.; Roshani, S. Online measuring density of oil products in annular regime of gas-liquid two phase flows. Measurement 2018, 129, 296-301. [CrossRef]

17. Mosorov, V.; Rybak, G.; Sankowski, D. Plug Regime Flow Velocity Measurement Problem Based on Correlability Notion and Twin Plane Electrical Capacitance Tomography: Use Case. Sensors 2021, 21, 2189. [CrossRef]

18. Vlasák, P.; Matoušek, V.; Chára, Z.; Krupička, J.; Konfršt, J.; Kesely, M. Concentration distribution and deposition limit of medium-coarse sand-water slurry in inclined pipe. J. Hydrol. Hydromech. 2020, 68, 83-91. [CrossRef]

19. Zych, M.; Hanus, R.; Vlasák, P.; Jaszczur, M.; Petryka, L. Radiometric methods in the measurement of particle-laden flows. Powder Technol. 2017, 318, 491-500. [CrossRef]

20. Roshani, M.; Sattari, M.A.; Ali, P.J.M.; Roshani, G.H.; Nazemi, B.; Corniani, E.; Nazemi, E. Application of GMDH neural network technique to improve measuring precision of a simplified photon attenuation based two-phase flowmeter. Flow Meas. Instrum. 2020, 75, 101804. [CrossRef]

21. Mosorov, V.; Zych, M.; Hanus, R.; Sankowski, D.; Saoud, A. Improvement of Flow Velocity Measurement Algorithms Based on Correlation Function and Twin Plane Electrical Capacitance Tomography. Sensors 2020, 20, 306. [CrossRef]

22. Roshani, M.; Phan, G.; Faraj, R.H.; Phan, N.-H.; Roshani, G.H.; Nazemi, B.; Corniani, E.; Nazemi, E. Proposing a gamma radiation based intelligent system for simultaneous analyzing and detecting type and amount of petroleum by-products. Nucl. Eng. Technol. 2021. [CrossRef]

23. Golijanek-Jędrzejczyk, A.; Mrowiec, A.; Hanus, R.; Zych, M.; Świsulski, D. Uncertainty of mass flow measurement using centric and eccentric orifice for Reynolds number in the range 10,000 $\leq \operatorname{Re} \leq 20,000$. Measurement 2020, 160, 107851. [CrossRef]

24. Zhang, F.; Chen, K.; Zhu, L.; Appiah, D.; Hu, B.; Yuan, S. Gas-Liquid Two-Phase Flow Investigation of Side Channel Pump: An Application of MUSIG Model. Mathematics 2020, 8, 624. [CrossRef]

25. Roshani, G.H.; Hanus, R.; Khazaei, A.; Zych, M.; Nazemi, E.; Mosorov, V. Density and velocity determination for single-phase flow based on radiotracer technique and neural networks. Flow Meas. Instrum. 2018, 61, 9-14. [CrossRef]

26. Chemical Cleaning. Available online: https://www.fourquest.com/services/chemical-cleaning (accessed on 15 February 2020).

27. Pelowitz, D.B. MCNP-X TM User's Manual, Version 2.5.0. LA-CP-05e0369; Los Alamos National Laboratory: New Mexico, NM, USA, 2005.

28. Nazemi, E.; Roshani, G.H.; Feghhi, S.A.H.; Setayeshi, S.; Zadeh, E.E.; Fatehi, A. Optimization of a method for iden-tifying the flow regime and measuring void fraction in a broad beam gamma-ray attenuation technique. Int. J. Hydrog. Energy 2016, 41, 7438-7444. [CrossRef]

29. Versaci, M.; Morabito, F.C. Image edge detection: A new approach based on fuzzy entropy and fuzzy divergence. Int. J. Fuzzy Syst. 2021, 1-19. [CrossRef]

30. Burrascano, P.; Ciuffetti, M. Early Detection of Defects through the Identification of Distortion Characteristics in Ultrasonic Responses. Mathematics 2021, 9, 850. [CrossRef]

31. Roshani, M.; Phan, G.; Roshani, G.H.; Hanus, R.; Nazemi, B.; Corniani, E.; Nazemi, E. Combination of X-ray tube and GMDH neural network as a nondestructive and potential technique for measuring characteristics of gas-oil-water three phase flows. Measurement 2021, 168, 108427. [CrossRef]

32. Versaci, M.; Angiulli, G.; di Barba, P.; Morabito, F.C. Joint use of eddy current imaging and fuzzy similarities to assess the integrity of steel plates. Open Phys. 2020, 18, 230-240. [CrossRef]

33. Pourjabar, S.; Choi, G.S. A High-Throughput Multi-Mode LDPC Decoder for 5G NR. arXiv 2021, arXiv:2102.13228.

34. Karami, A.; Yousefi, T.; Harsini, I.; Maleki, E.; Mahmoudinezhad, S. Neuro-Fuzzy Modeling of the Free Convection Heat Transfer from a Wavy Surface. Heat Transf. Eng. 2015, 36, 847-855. [CrossRef]

35. Darbandi, M.; Ramtin, A.R.; Sharafi, O.K. Tasks mapping in the network on a chip using an improved optimization algorithm. Int. J. Pervasive Comput. Commun. 2020, 16, 165-182. [CrossRef] 
36. Moradi, M.J.; Roshani, M.M.; Shabani, A.; Kioumarsi, M. Prediction of the load-bearing behavior of spsw with rectangular opening by RBF net-work. Appl. Sci. 2020, 10, 1185. [CrossRef]

37. Abolhasani, M.; Karami, A.; Rahimi, M. Numerical Modeling and Optimization of the Enhancement of the Cooling Rate in Concentric Tubes Under Ultrasound Field. Numer. Heat Transf. Part A Appl. 2015, 67, 1282-1309. [CrossRef]

38. Jamshidi, M.B.; Lalbakhsh, A.; Talla, J.; Peroutka, Z.; Hadjilooei, F.; Lalbakhsh, P.; Jamshidi, M.; La Spada, L.; Mirmozafari, M.; Dehghani, M.; et al. Artificial intelligence and COVID-19: Deep learning approaches for diagnosis and treatment. IEEE Access 2020, 8, 109581-109595. [CrossRef]

39. Xue, H.; Yu, P.; Zhang, M.; Zhang, H.; Wang, E.; Wu, G.; Li, Y.; Zheng, X. A Wet Gas Metering System Based on the Extended-Throat Venturi Tube. Sensors 2021, 21, 2120. [CrossRef]

40. Moradi, M.; Daneshvar, K.; Ghazi-Nader, D.; Hajiloo, H. The prediction of fire performance of concrete-filled steel tubes (CFST) using artificial neural network. Thin Walled Struct. 2021, 161, 107499. [CrossRef]

41. Aghakhani, M.; Ghaderi, M.R.; Karami, A.; Derakhshan, A.A. Combined effect of TiO2 nanoparticles and input welding parameters on the weld bead penetration in submerged arc welding process using fuzzy logic. Int. J. Adv. Manuf. Technol. 2014, 70, 63-72. [CrossRef]

42. Jamshidi, M.B.; Roshani, S.; Talla, J.; Roshani, S.; Peroutka, Z. Size reduction and performance improvement of a microstrip Wilkinson power divider using a hybrid design technique. Sci. Rep. 2021, 11, 1-15. [CrossRef]

43. Roshani, G.H.; Nazemi, E.; Feghhi, S.A.H.; Setayeshi, S. Flow regime identification and void fraction prediction in two-phase flows based on gamma ray attenuation. Measurement 2015, 62, 25-32. [CrossRef]

44. Arabi, M.; Dehshiri, A.M.; Shokrgozar, M. Modeling transportation supply and demand forecasting using artificial intelligence parameters (Bayesian model). J. Appl. Eng. Sci. 2018, 16, 43-49. [CrossRef]

45. Salimi, J.; Ramezanianpour, A.M.; Moradi, M.J. Studying the effect of low reactivity metakaolin on free and restrained shrinkage of high performance concrete. J. Build. Eng. 2020, 28, 101053. [CrossRef]

46. Roshani, G.H.; Nazemi, E.; Feghhi, S.A.H. Investigation of using 60Co source and one detector for determining the flow regime and void fraction in gas-liquid two-phase flows. Flow Meas. Instrum. 2016, 50, 73-79. [CrossRef]

47. Lotfi, S.; Roshani, S.; Roshani, S. Design of a miniaturized planar microstrip Wilkinson power divider with harmonic cancellation. Turk. J. Electr. Eng. Comput. Sci. 2020, 28, 3126-3136. [CrossRef]

48. Karami, A.; Veysi, F.; Mohebbi, S.; Ghashghaei, D. Optimization of Laminar Free Convection in a Horizontal Cavity Consisting of Flow Diverters Using ICA. Arab. J. Sci. Eng. 2014, 39, 2295-2306. [CrossRef]

49. Khaleghi, M.; Salimi, J.; Farhangi, V.; Moradi, M.J.; Karakouzian, M. Application of Artificial Neural Network to Predict Load Bearing Capacity and Stiffness of Perfo-rated Masonry Walls. CivilEng 2021, 2, 48-67. [CrossRef]

50. Roshani, G.H.; Nazemi, E.; Roshani, M.M. Usage of two transmitted detectors with optimized orientation in order to three phase flow metering. Measurement 2017, 100, 122-130. [CrossRef]

51. Pirasteh, A.; Roshani, S.; Roshani, S. Compact microstrip lowpass filter with ultrasharp response using a square-loaded modified T-shaped resonator. Turk. J. Electr. Eng. Comput. Sci. 2018, 26, 1736-1746. [CrossRef]

52. Arief, H.A.; Wiktorski, T.; Thomas, P.J. A Survey on Distributed Fibre Optic Sensor Data Modelling Techniques and Machine Learning Algorithms for Multiphase Fluid Flow Estimation. Sensors 2021, 21, 2801. [CrossRef]

53. Roshani, S.; Roshani, S. Two-Section Impedance Transformer Design and Modeling for Power Amplifier Applications. Appl. Comput. Electromagn. Soc. J. 2017, 32, 1042-1047.

54. Roshani, G.H.; Nazemi, E.; Roshani, M.M. Intelligent recognition of gas-oil-water three-phase flow regime and determination of volume fraction using radial basis function. Flow Meas. Instrum. 2017, 54, 39-45. [CrossRef]

55. Jahanshahi, A.; Sabzi, H.Z.; Lau, C.; Wong, D. GPU-NEST: Characterizing Energy Efficiency of Multi-GPU Inference Servers. IEEE Comput. Archit. Lett. 2020, 19, 139-142. [CrossRef]

56. Roshani, G.H.; Nazemi, E.; Roshani, M.M. Identification of flow regime and estimation of volume fraction independent of liquid phase density in gas-liquid two-phase flow. Prog. Nucl. Energy 2017, 98, 29-37. [CrossRef]

57. Moradi, M.J.; Hariri-Ardebili, M.A. Developing a library of shear walls database and the neural network based predictive meta-model. Appl. Sci. 2019, 9, 2562. [CrossRef]

58. Roshani, S.; Jamshidi, M.B.; Mohebi, F.; Roshani, S. Design and Modeling of a Compact Power Divider with Squared Resonators Using Artificial Intelligence. Wirel. Pers. Commun. 2020. [CrossRef]

59. Jahanshahi, A.; Taram, M.K.; Eskandari, N. Blokus Duo game on FPGA. In Proceedings of the 17th CSI International Symposium on Computer Architecture \& Digital Systems (CADS 2013), Tehran, Iran, 30-31 October 2013; pp. 149-152.

60. Bavandpour, S.K.; Roshani, S.; Pirasteh, A.; Roshani, S.; Seyedi, H. A compact lowpass-dual bandpass diplexer with high output ports isolation. AEU Int. J. Electron. Commun. 2021, 135, 153748. [CrossRef]

61. Roshani, G.H.; Nazemi, E. Intelligent densitometry of petroleum products in stratified regime of two phase flows using gamma ray and neural network. Flow Meas. Instrum. 2017, 58, 6-11. [CrossRef]

62. Jahanshahi, A. TinyCNN: A Tiny Modular CNN Accelerator for Embedded FPGA. arXiv 2019, arXiv:1911.06777.

63. Sattari, M.A.; Roshani, G.H.; Hanus, R.; Nazemi, E. Applicability of time-domain feature extraction methods and artificial intelligence in two-phase flow meters based on gamma-ray absorption technique. Measurement 2021, 168, 108474. [CrossRef] 
64. Nabavi, M.; Elveny, M.; Danshina, S.D.; Behroyan, I.; Babanezhad, M. Velocity prediction of Cu/water nanofluid convective flow in a circular tube: Learning CFD data by differential evolution algorithm based fuzzy inference system (DEFIS). Int. Commun. Heat Mass Transf. 2021, 126, 105373. [CrossRef]

65. Karami, A.; Roshani, G.H.; Nazemi, E.; Roshani, S. Enhancing the performance of a dual-energy gamma ray based three-phase flow meter with the help of grey wolf optimization algorithm. Flow Meas. Instrum. 2018, 64, 164-172. [CrossRef] 